\title{
Safety evaluation of nuclear power plant based on multiscale analyses
}

\author{
T Watanabe \\ 1. University of Fukui, Japan
}

\begin{abstract}
A loss-of-coolant accident of nuclear power plant is simulated using the system analysis code. The analytical condition is based on the international standard problem 26 conducted with the integral effect test facility. The experimental analysis is also performed, and the result of plant analysis is compared with the experiment and the experimental analysis. The discharge coefficient of critical flow model is determined so as to obtain the agreement of reactor pressure between the experiment and the experimental analysis and is used for the plant analysis. The thermalhydraulic phenomena in the experiment such as core heat up are simulated well by the two analyses, while some problems in the experiment for simulating plant accidents are made clear. Parametric sensitivity analyses of plant accidents are performed as an example of reliable safety evaluation using the validated plant model.
\end{abstract}

\section{INTRODUCTION}

Loss of coolant accidents (LOCAs) are one of the most significant accidents among the design basis accidents of nuclear reactors, and many research works have been performed so far including experiments and numerical analyses. The plant system behaviours are obtained using the best estimate system analysis codes such as RELAP [1] and TRAC [2], and the plant safety and operator actions are evaluated. The calculated plant behaviours under various conditions are used not only for the safety evaluation [3] but also as the data bases for machine learning [4] since the plant accident data are limited. In these analyses, a base case analysis is performed first, and the accuracy of base case result is checked by comparing with other calculated results or plant data. Parametric sensitivity analyses are performed next based on the base case analysis. Furthermore, the results of plant system analyses are used as the boundary conditions not only for the detailed thermal-hydraulic analyses based on the computational fluid dynamics approach [5] but also for the transient structural analyses [6]. The reliability of plant system analyses is thus of importance for the nuclear reactor safety.

In order to validate the system analysis codes to simulate the plant behaviours, large-scale system experiments so called integral effect tests (IETs) are utilized. The international standard problems (ISPs) are one of the important projects for improving the system analysis codes [7]. The selected experimental data obtained at some IET facilities are distributed to the ISP participants, and the experimental analyses are performed using the system analysis codes. By comparing the analytical results with each other and with the IET result, the capability of codes and models is discussed and improved. The cold-leg break LOCA experiment was conducted with the Large-Scale Test Facility (LSTF) at Japan Atomic Energy Research Institute as the ISP 26 [8].

${ }^{\star}$ Corresponding Author: twata@u-fukui.ac.jp 
Characteristics of thermal-hydraulic phenomena during the accident with a failure of highpressure injection system were discussed as well as the characteristics of safety analysis codes, and the analytical results were shown to depend on code users $[8,9]$. The user effects are significant for large scale analyses such as the plant analyses and the IET analyses. Several code users including engineers of software companies are generally involved in these analyses, since the vast knowledge of plant and IET systems such as the design, operating conditions and control procedures is necessary for developing analytical models. Furthermore, the knowledge of physical models and numerical characteristics of the codes is needed.

When the plant transient is compared with the IET result, the differences between the plant and IET facilities including component size and operating conditions are of importance. When the steam generator tube rupture accident occurred at the Mihama Unit-2 power plant in Japan, the LSTF experiment was conducted to simulate the accident, and analyzed using the RELAP code $[10,11]$. The accident data were limited to several plant parameters, but many measurement data were obtained by the experiment. Both the plant accident analysis and the experimental analysis were performed using the TRAC code [12], and the thermal-hydraulic phenomena during the plant accident were shown to be simulated well by the LSTF experiment. The applicability of LSTF experimental data to the safety evaluation of European type reactors was also discussed [13].

In this study, the analysis of power plant cold-leg break LOCA with the condition of ISP 26 is performed. The experimental analysis of ISP 26 is also performed, and the plant analysis is compared with the experiment and the experimental analysis. The transient behaviour of power plant is shown to be similar to those of the experiment and the experimental analysis, but some problems in the experiment for simulating plant accidents are made clear. Sensitivity analyses are performed using the same plant model as an example of safety evaluation using validated plant models.

\section{COLD-LEG BREAK LOCA}

The condition of a cold-leg break LOCA is based on the ISP 26 experiment [8]. The LSTF is the world largest IET facility for simulating plant behaviours, and various types of accidents and transients have been simulated and reported [14]. The experimental data are valuable not only for improving the system analysis codes but also for validating plant analyses. One of the LOCA experiments conducted with the LSTF is used in this study as a sample case. The LSTF is a 1/48 volumetrically scaled model of a Westinghouse-type 3423 MWt four-loop pressurized water reactor (PWR) [15,16]. The LSTF has the same major component elevations as the PWR plant as shown in Figure 1 to simulate the natural circulation phenomena, and is designed to be operated at the same high pressures and temperatures as the PWR. The equipment of LSTF can be controlled in the same way as that of the PWR to simulate operational transients. Fuel rods are simulated by electrical heater rods. The four primary loops of PWR are represented by two equal-volume loops. Over 2500 instruments are available for various types of measurements including pressures, fluid and wall temperatures, flow rates, and so on.

The horizontal break line piping was connected to the cold leg without the pressurizer for the ISP 26 experiment. The break orifice was located in the break line, and its flow area corresponded to $5 \%$ of the PWR cold-leg cross sectional area. The steady state condition simulating the PWR operating condition was established, and the break experiment was started by opening the break valve in the break line. 
The reactor scram occurred at a pressurizer pressure of $12.97 \mathrm{MPa}$, and the coolant pumps were tripped, and the core power began to decrease along the pre-programmed decay heat curve. The auxiliary feed water system and the high-pressure injection system were assumed to fail. The accumulator injection system was actuated at the reactor pressure of $4.51 \mathrm{MPa}$.

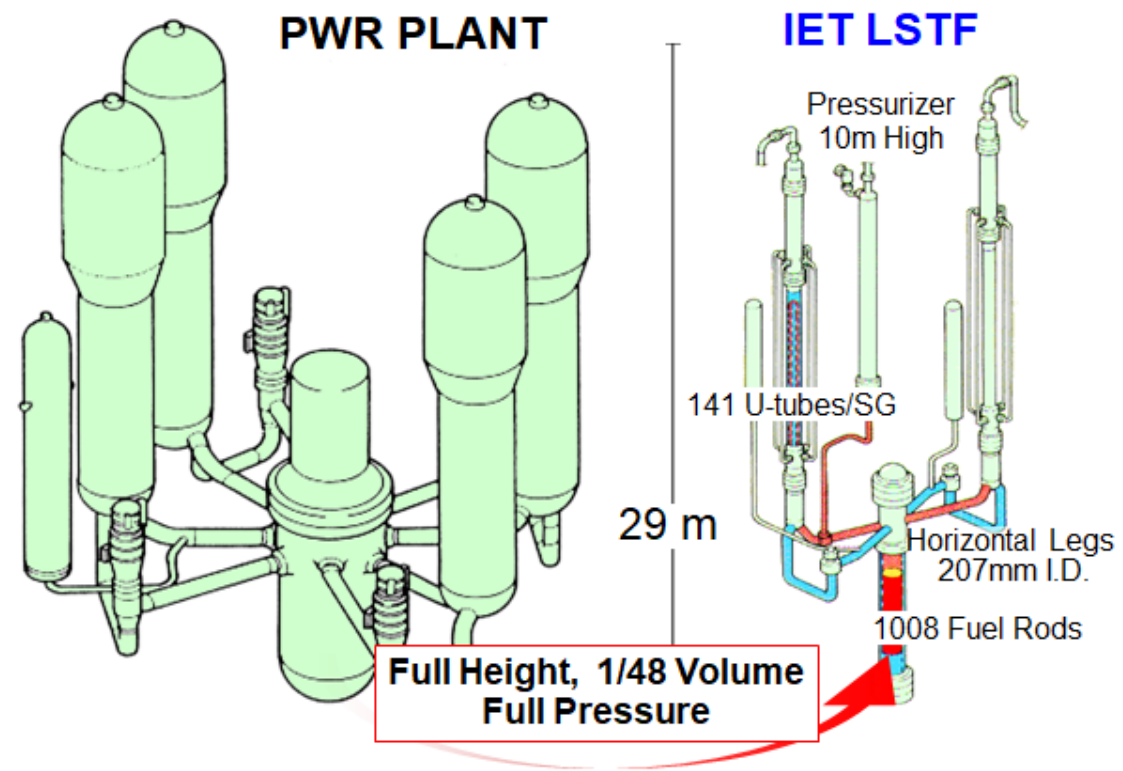

Figure 1: PWR plant and IET LSTF.

\section{PWR PLANT ANALYSIS AND LSTF EXPERIMENTAL ANALYSIS}

\subsection{Analytical Model}

The PWR plant analysis and the LSTF experimental analysis are performed using the RELAP code [1]. The analytical model for PWR plant shown in Figure 2 is developed according to the specifications of the typical four-loop PWR in Japan [17]. Three intact loops are represented by one loop with three-times larger cross-sectional area. The PWR analytical model, thus, has two loops with different size. The reactivity table, which is used for calculating the decay heat from the nuclear fuels, is slightly modified, since the decay heat curve used for the heater rod in the LSTF experiment gives the slower decrease due to the conservative setting [8]. The calculation parameters and models including the critical flow model and discharge coefficient are the same as those used for the LSTF experimental analysis. The analytical model for LSTF experiment shown in Figure 3 is developed based on the LSTF specifications $[15,16]$. The Henry-Fauske critical flow model [1] is applied with the discharge coefficient of 0.75 according to the preliminary calculations. 


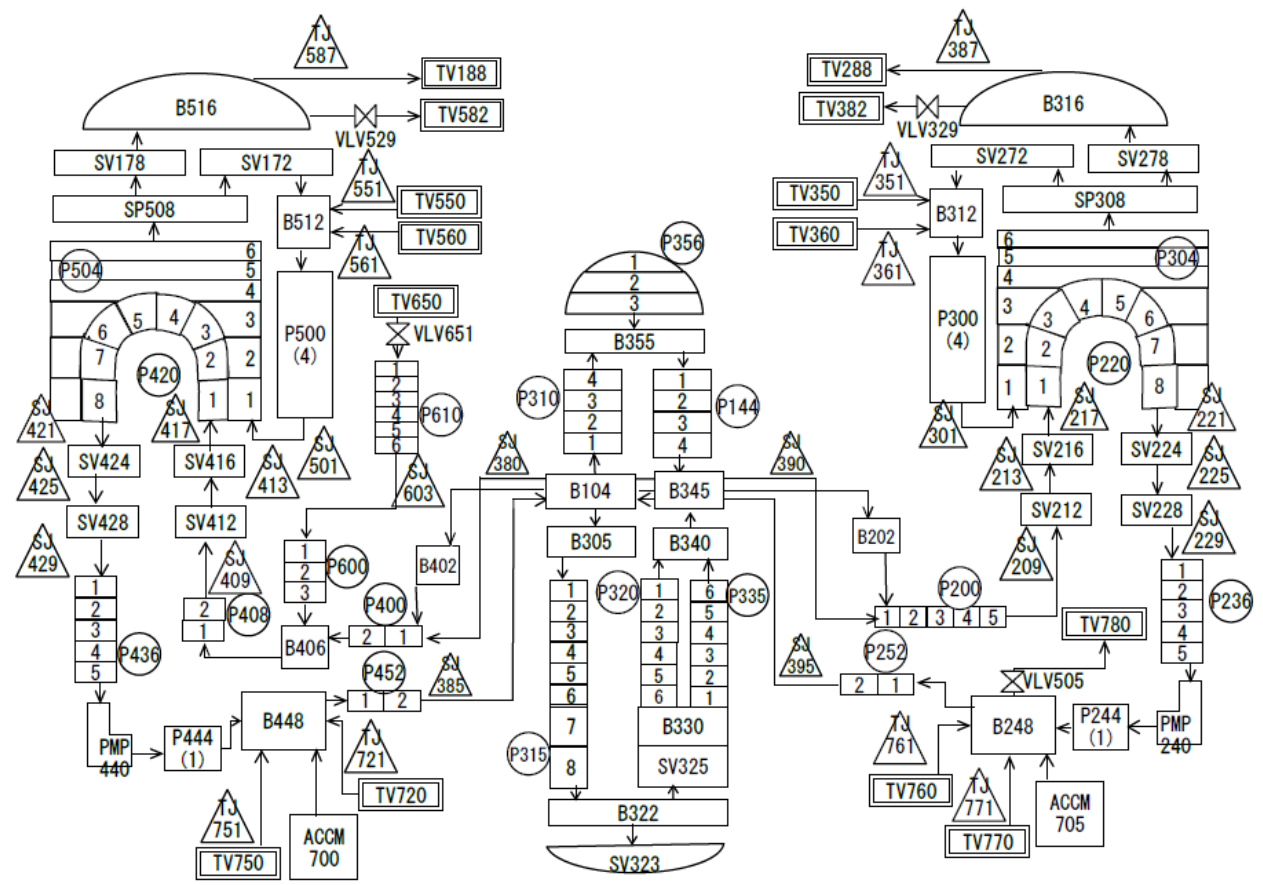

Figure 2: Analytical model for PWR plant.

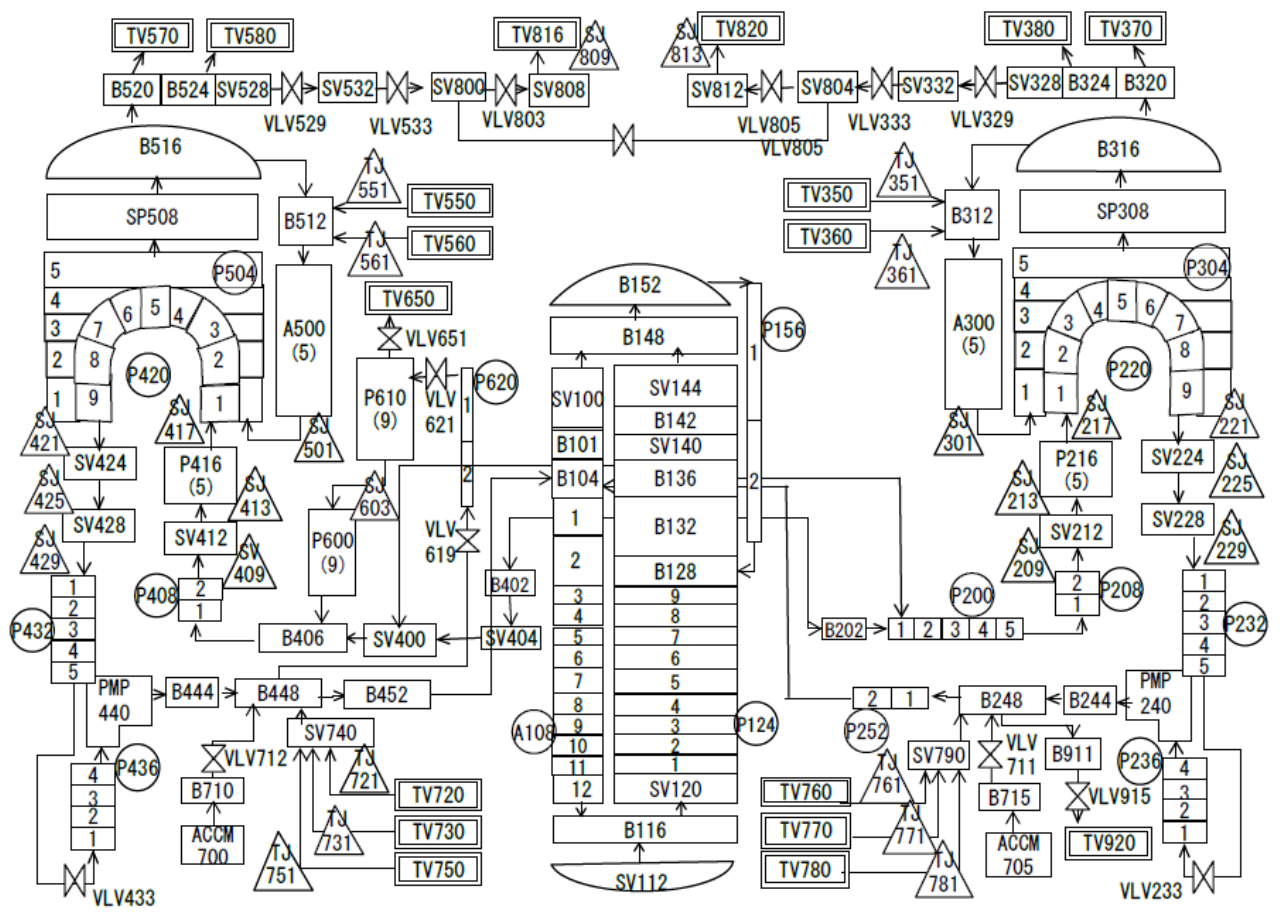

Figure 3: Analytical model for LSTF experiment. 


\subsection{Comparison between Analytical Results and Experimental Data}

The transient of reactor pressure is shown in Figure 4, where the experimental data are indicated by "LSTF Exp." and analytical results for LSTF and PWR are by "LSTF RELAP" and "PWR RELAP", respectively. The reactor pressure decreases rapidly after the break valve opening at time zero due to the single-phase liquid discharge. The two-phase discharge follows and the pressure decrease becomes small at around $100 \mathrm{~s}$. The discharge flow becomes singlephase steam at around $150 \mathrm{~s}$ and the pressure decreases constantly afterward. It is seen that the agreement between the analytical results and experimental data is satisfactory during the transient, and it is found that the critical flow model and the discharge coefficient are appropriately selected. Although the PWR analysis agrees well with the experimental analysis over the whole transient, the PWR pressure decreases more rapidly during the single- and twophase discharge periods. This is because the core power decreases more rapidly in the PWR analysis than in the experimental analysis. The reactor core power is shown in Figure 5 along with that used for the experimental analysis, which was also used for the experiment itself. The PWR core power is multiplied by the LSTF scaling ratio of 1/48 in Figure 5. The LSTF core power decreases slowly comparing with the standard reactor power [8]. Although the reactivity table is slightly modified to simulate the slower decrease, the core power for the PWR analysis is still smaller up to about $300 \mathrm{~s}$. The initial pressure decrease is thus larger for the PWR analysis.

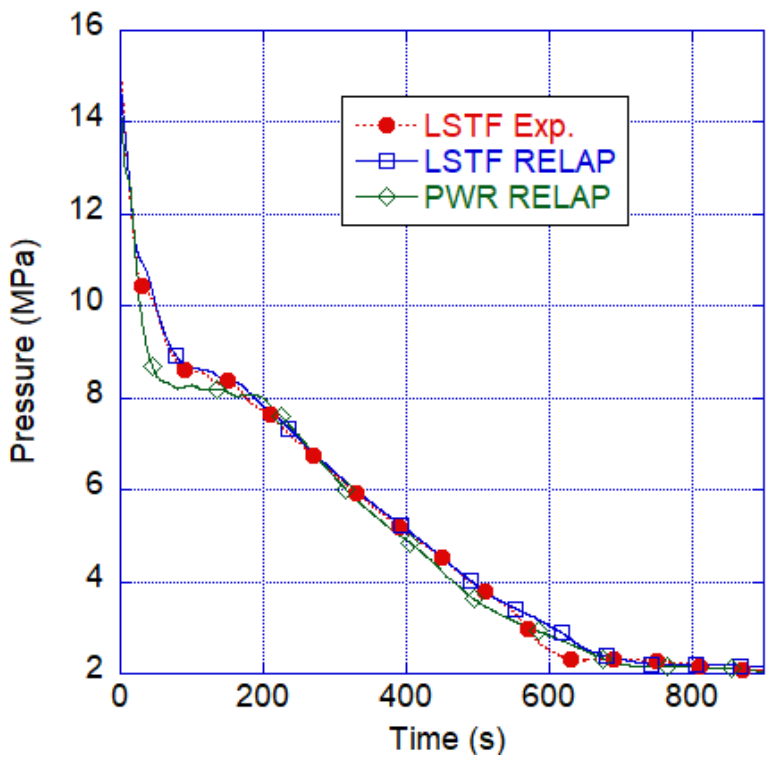

Figure 4. Reactor pressure. 


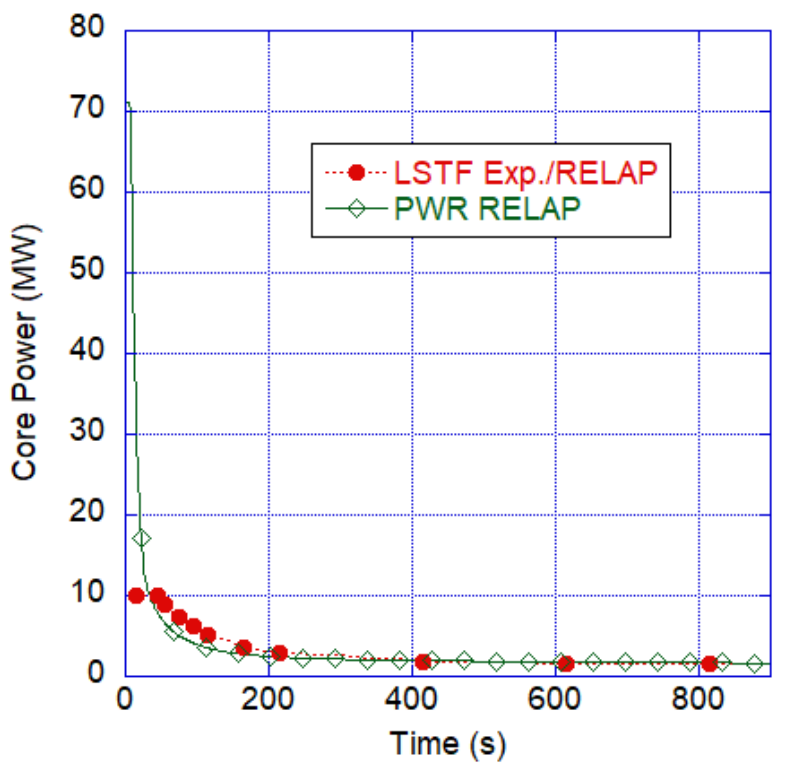

Figure 5. Reactor core power.

The discharge flow rate from the break is shown in Figure 6, where the PWR result is multiplied by $1 / 48$ to compare with the experimental analysis. The Henry-Fauske critical flow model [1] is used, and the discharge coefficient is 0.75 for both the analyses. The experimental analysis agrees well with the experiment during the initial single-phase discharge, slightly underestimates during the two-phase discharge, and agrees well again during the steam discharge afterward. The PWR discharge flow rate during the single- and two-phase discharge periods is smaller than the experimental analysis due to the rapid decrease in reactor pressure shown in Figure 4. The discharge flow rate in the experiment was obtained as the time variation of water level in the catch tank $[15,16]$, since the steam-water two-phase flow rate is difficult to measure directly. The experimental data are thus accompanied with large oscillations in Figure 6.

The discharge flow rate is one of the most important parameters for the LOCA analyses since the discharge flow is the outflow boundary condition and the pressure transient is closely related to the discharge flow rate. The same critical flow model and the discharge coefficient are used for the PWR and experimental analyses in this study, and the effect of using different discharge coefficients is eliminated. This is not always the case with the PWR and IET analyses even though the same code is used [12]. As a result, the reactor pressure and the discharge flow rate are shown to be affected by the core power, and the decay heat curve used in the IET is found to be one of the important parameters for reliable accident analyses.

It is noted that the break line piping equipped with the break valve and orifice was used in the experiment. The break line was a branching pipe connected to the cold leg and is modelled in the experimental analysis. The effect of the break line was evaluated by sensitivity calculations and found to be negligible for the PWR analysis. 


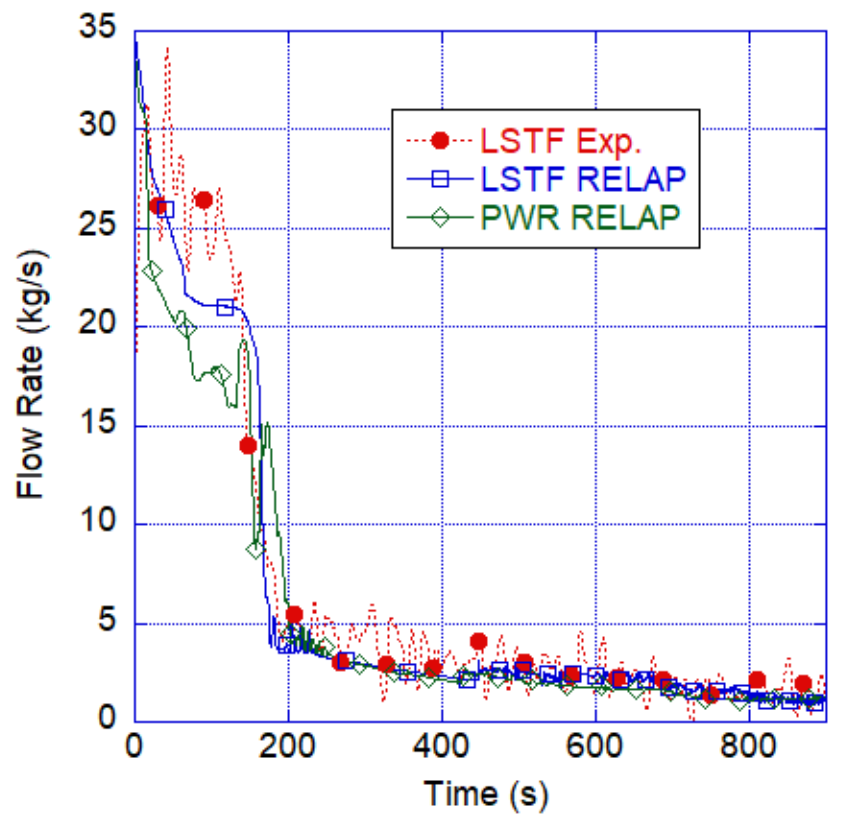

Figure 6. Discharge flow rate.

The high-pressure injection system was assumed to fail in this experiment, and the accumulator was used alone as the safety injection system. The accumulator flow rates, which are the inflow boundary condition for the transient, are shown in Figures 7 and 8, respectively, for the intact and broken loops. The timing of injection is almost the same for both the experiment and analyses, since the reactor pressure is correctly calculated as shown in Figure 4. The experimental flow rates are slightly higher than the analytical ones at around $600 \mathrm{~s}$, corresponding to the low pressure in the experiment shown in Figure 4. It is noted that the injection flow rate is much higher for the intact loop. The initial water level in the accumulator tank was set to be higher for the broken loop in the experiment so that the ratio of injection rate would be 1:3 for the broken and intact loops [8]. The initial water levels for the experimental analysis are the same as those for the experiment, while the nominal operating levels are used for the PWR analysis.

The loop flow rates are shown in Figures 9 and 10, respectively, for the intact and broken loops. The intact loop for PWR analysis represents three intact loops, while two equal loops are used in the experimental analysis and the experiment. In order to compare the PWR results with the experimental analysis in Figures 9 and 10, the flow rates in PWR analysis are multiplied by $1 / 48$ first, and the intact loop flow rate is multiplied by $2 / 3$, and the remaining $1 / 3$ of the intact loop flow rate is added to the broken loop flow rate. The PWR results are then in good agreement with the experimental analysis, while the experimental data, which were shown in the ISP-26 report [8] as the loop flow rates, are much higher than the analytical results. These experimental data were obtained in the loop seal section, which is the lowest section of the loop piping shown in Figure 1 and the gamma-ray densitometer was equipped to measure the flow density $[15,16]$. 
The densitometer had a single beam in the vertical direction, and the obtained flow density is probably affected by the accumulated water in the loop seal bottom during the steam discharge period. The experimental results shown in Figures 9 and 10 are thus much higher than the analytical results.

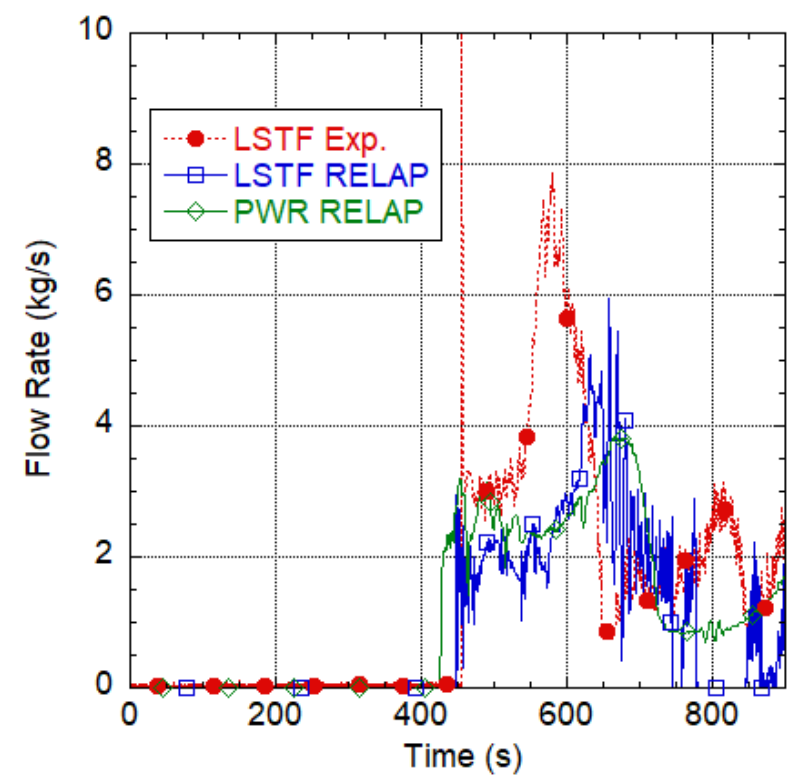

Figure 7: Accumulator flow rate (intact loop)

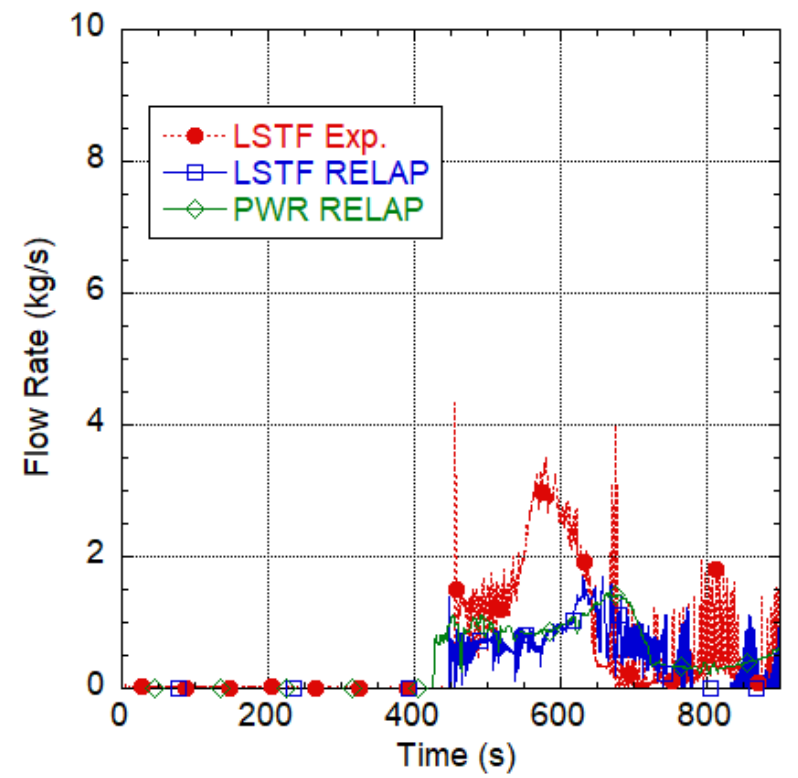

Figure 8: Accumulator flow rate (broken loop) 


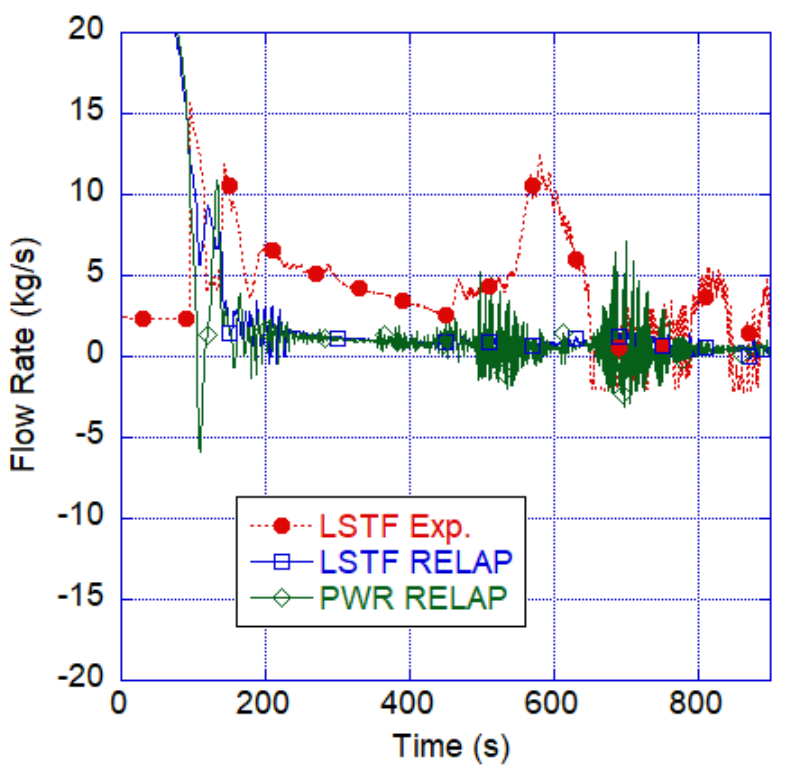

Figure 9: Coolant flow rate (intact loop).

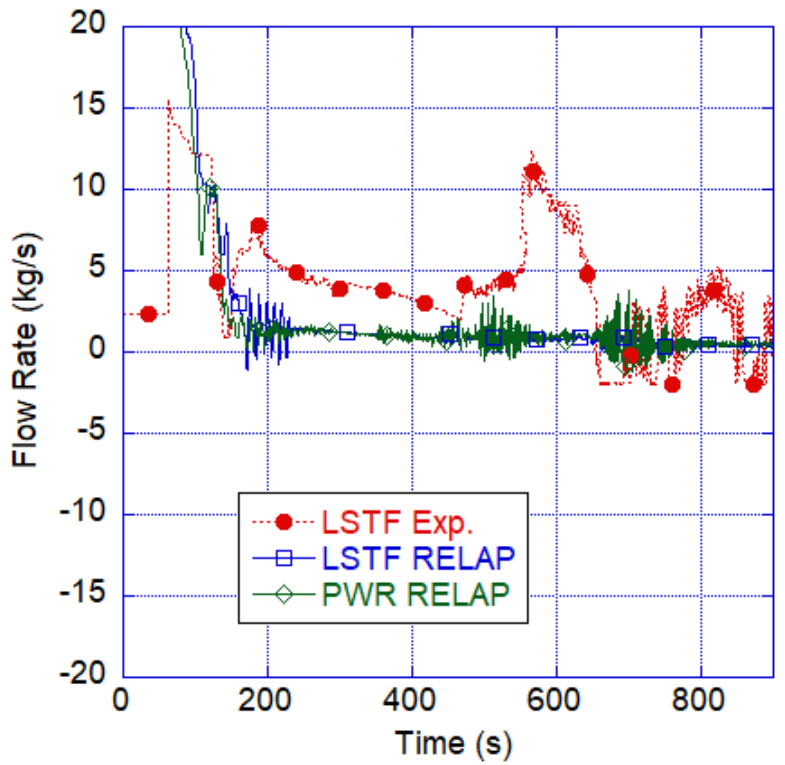

Figure 10: Coolant flow rate (broken loop). 
In order to check the loop flow rates, the cold-leg flow rates are shown in Figures 11 and 12 , respectively, for the intact and broken loops. These experimental results were obtained in the cold legs, where the water was not accumulated and the flow density was measured using the three-beam gamma-ray densitometer $[15,16]$. The flow density is thus reliable to calculate the flow rate. The intact loop flow rates shown in Figure 11 decrease during the single- and two-phase discharge periods. The flow rates then become stable before the accumulator injection, though the experimental data are slightly larger than the analytical results. The broken loop flow rates in Figure 12 decrease to the negative value, since the location of flow rate measurement is in between the break point and the reactor pressure vessel. The cold-leg flow rates are much oscillated after the accumulator injection in Figures 11 and 12 due to condensation. The analytical results agree well with the experimental data not in Figures 9 and 10, but in Figures 11 and 12. It is thus found in these figures that the experimental data should also be checked as well as the measurement method to compare with the analytical results.

The differential pressure in the reactor core, which corresponds to the amount of coolant, is shown in Figure 13. The experimental differential pressure decreases after break during the single- and two-phase discharge periods and becomes stable after the lowest peak at about 150 s corresponding to the timing of loop-seal clearing, then decreases again at around $400 \mathrm{~s}$ due to the boil off. The reactor pressure reaches the accumulator set point during the boil-off period, and the differential pressure starts to increase at around $450 \mathrm{~s}$. The characteristics of differential pressure are simulated well by the experimental analysis, while the decrease in differential pressure is slightly earlier for the PWR analysis. This might be due to the difference of core structure between the PWR and experimental analyses. The LSTF has no bypass region, and the scaling ratio of the cross-sectional area is slightly different from the volume scaling ratio $[15,16]$.

The surface temperatures of heater rods in the experiment observed at the elevation of 3.05 $\mathrm{m}$ are shown in Figure 14. High, middle and low power rods were used in the experiment, and the observed temperatures were much different according to the power level and the horizontal locations even at the same elevation. The average temperatures for each power level are thus shown in Figure 14. It is noted that the peak values of these average temperatures are lower than those shown in the ISP-26 report [8], in which one of the highest temperature rods was selected to show the heat up. The surface temperatures of heater rod and fuel rod, respectively, in the experimental and PWR analyses are also shown in Figure 14. The first peak at around $150 \mathrm{~s}$ is the heat up corresponding to the loop-seal clearing and the second one at around 450 $\mathrm{s}$ is the boil off. The first peak was observed in some high and middle power rods in the experiment, while not calculated in the analyses using the average power rod. The timing and duration of temperature increase for the second heat up are simulated well by the experimental analysis, since the reactor core differential pressure is simulated well as shown in Figure 13, while the timing is slightly earlier for the PWR analysis due the earlier decrease in differential pressure. 


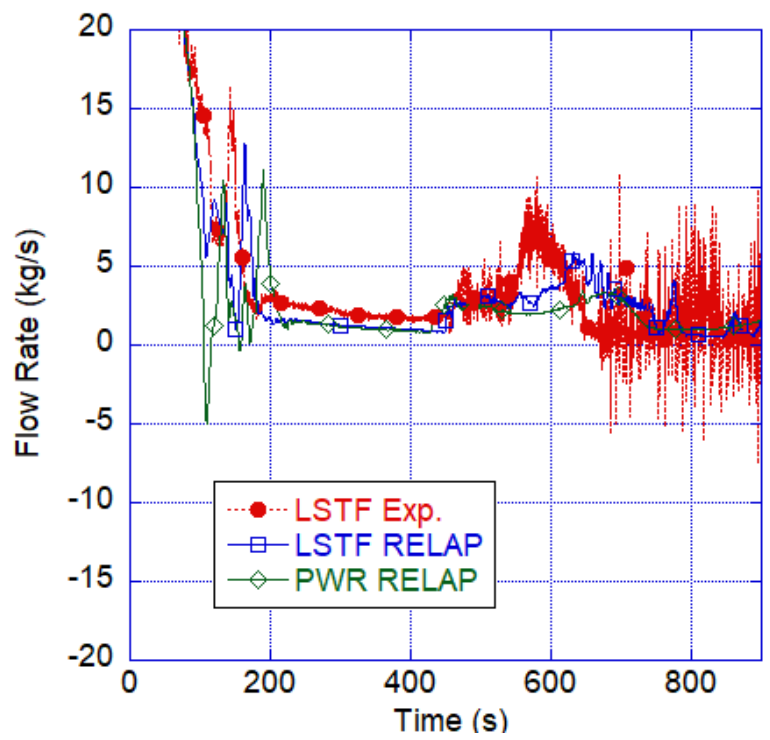

Figure 11: Cold-leg flow rate (intact loop).

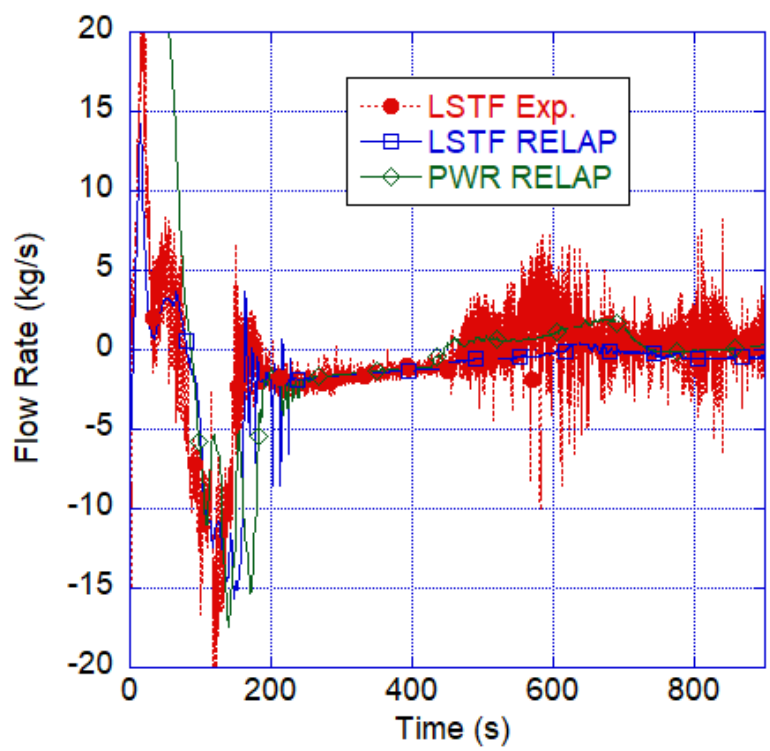

Figure 12: Cold-leg flow rate (broken loop). 


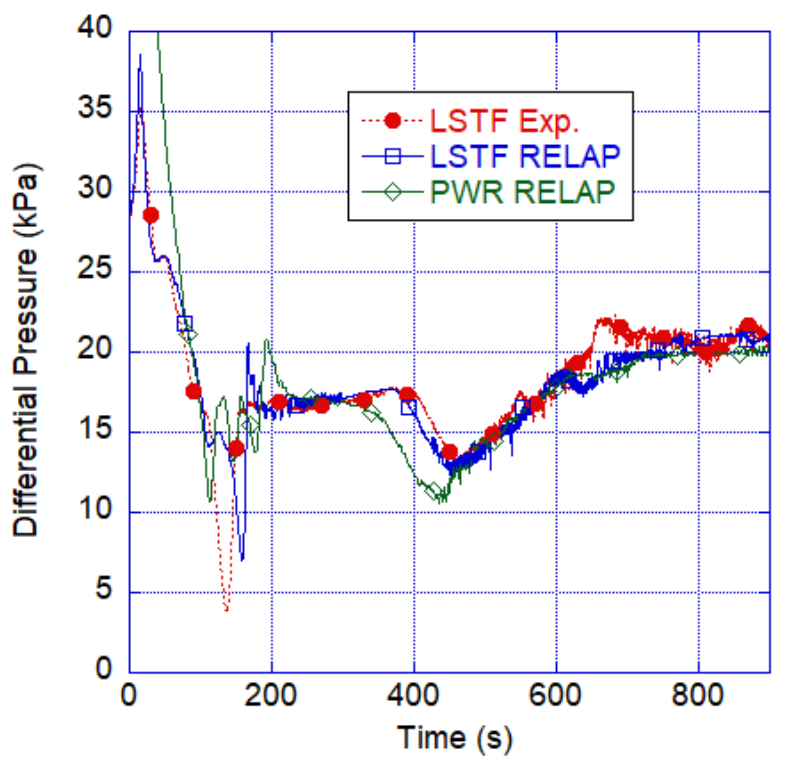

Figure 13: Reactor core differential pressure.

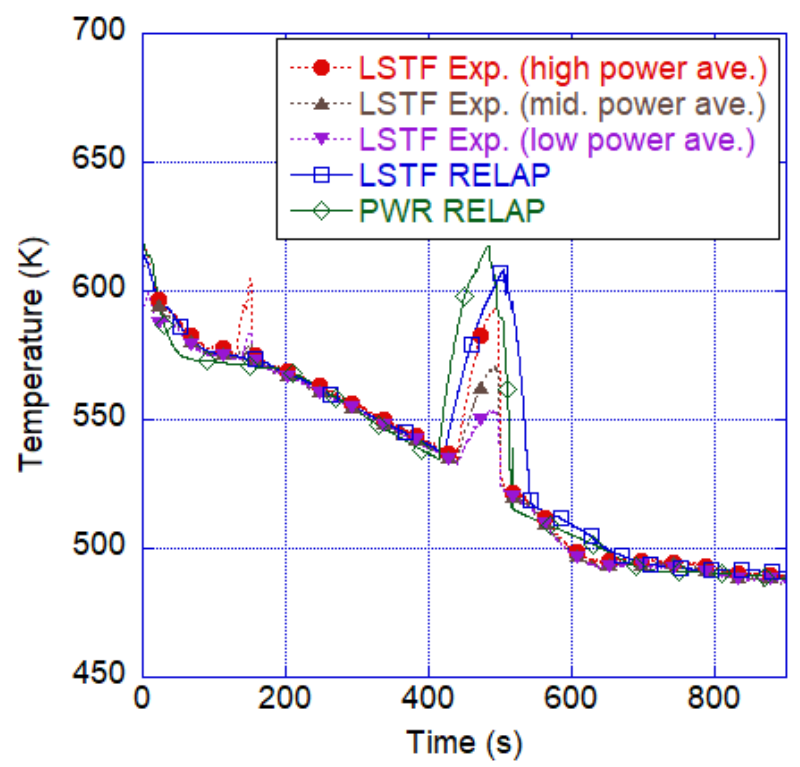

Figure 14: Rod surface temperature. 


\section{PWR PLANT SENSITIVETY ANALYSES}

The overall transient of PWR plant during the cold-leg break LOCA is found to be similar to that of the experimental analysis as shown in Figures 4-14. The PWR plant analysis model is thus validated, and then used for sensitivity analyses. The sample cases are the cold-leg break LOCA with different break sizes: 4, 6 and 8 inches $(10.16 \mathrm{~cm}, 15.24 \mathrm{~cm}$ and $20.32 \mathrm{~cm})$. These break sizes are often used for the case studies to check the thermal-hydraulic behaviors [18]. The break sizes of 4, 6 and 8 inches correspond to 2.1, 4.8 and $8.5 \%$ of the PWR cold-leg cross-sectional area, respectively. The PWR plant analysis model and the parameters are the same as before, and the break size is changed alone in the following.

The transients of reactor pressure are shown in Figure 15. The characteristics of pressure transients are the same as those shown in Figure 4: the rapid pressure decrease due to the single-phase liquid discharge, the slight decrease due to the two-phase discharge, and the slow decrease due to the single-phase steam discharge. The discharge flow rates are shown in Figure 16. The relationship between the discharge flow rate and the reactor pressure is the same as that in Figures 6 and 4. It is noted that the factor of 1/48 is not multiplied in Figure 16. The reactor core differential pressures and the rod surface temperatures are shown in Figures 17 and 18, respectively. It is shown in Figure 17 that the timing of decrease in differential pressure is earlier for larger break sizes due to larger discharge flow rate. The timing of increase is also earlier for larger break sizes due to earlier accumulator injection. The reactor pressure for the smallest break size is not decreased to the accumulator injection set point in Figure 15, and the rod surface temperature continues to increase as shown in Figure 18. The surface temperature for the largest break size does not increase on the contrary, since the reactor pressure decreases rapidly, and the accumulator injection starts earlier.

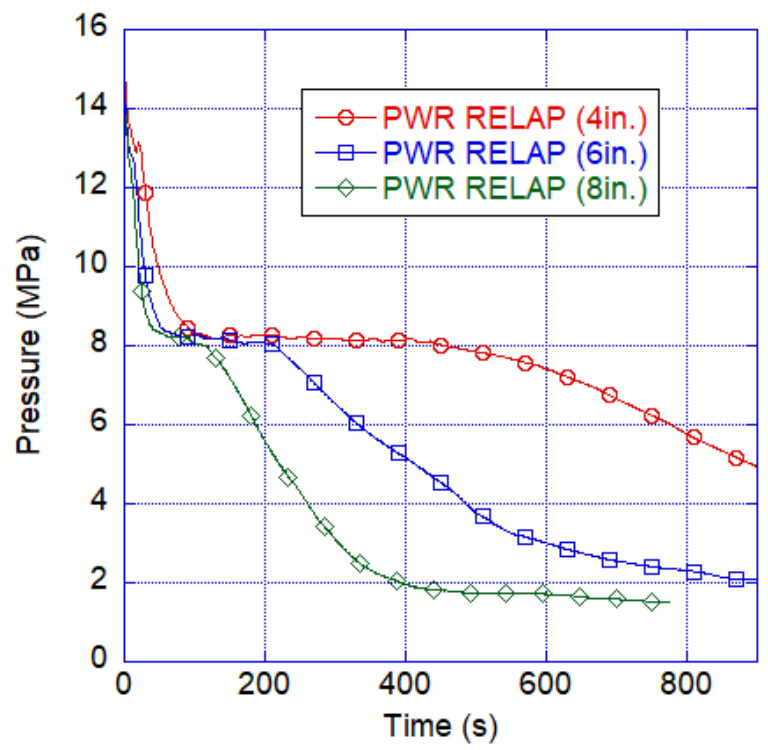

Figure 15: Reactor pressure. 


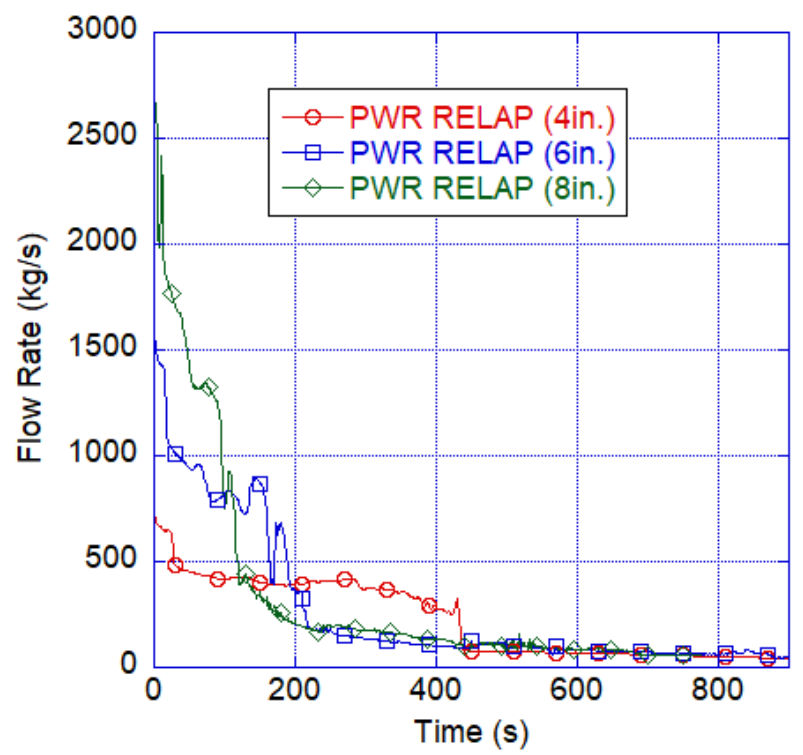

Figure 16: Discharge flow rate

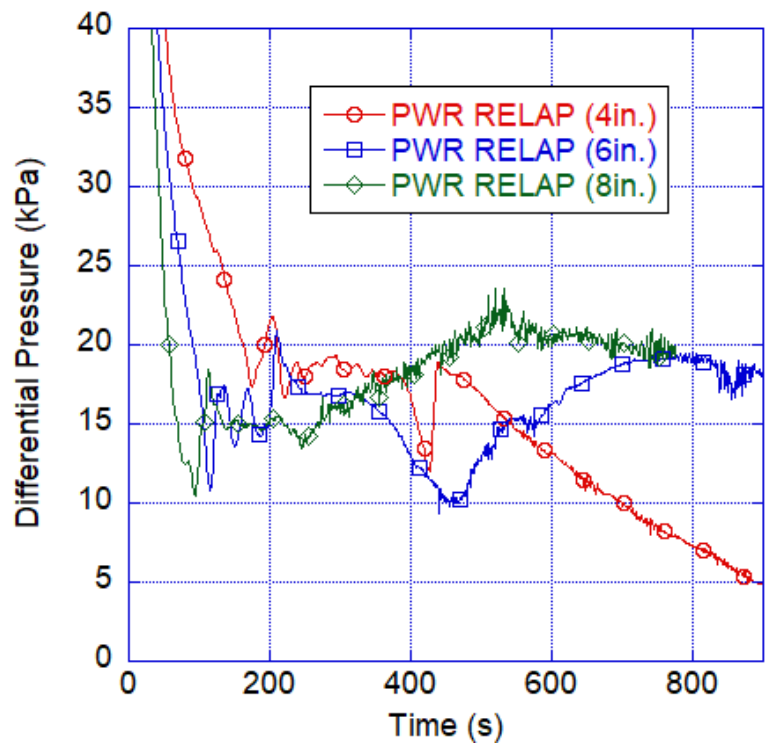

Figure 17: Reactor core differential pressure 


\section{CONCLUSION}

The analysis of nuclear power plant cold-leg break LOCA has been performed using the system analysis code. The experimental data by the IET LSTF, which were selected as the ISP-26, were also utilized. The analytical models for the power plant and the IET were developed with the same modelling procedure and parameters, and the plant and experimental analyses were performed. The transient phenomena in the plant and experimental analyses were in good agreement with those in the experiment, and the analytical models and parameters including discharge coefficient of critical flow model were proved to be selected appropriately. Some problems in the experiment were made clear: the core power, loop flow rates, and rod surface temperature. The parametric sensitivity calculations for the power plant were performed using the validated plant model. The reliability of safety evaluation and accident data bases for nuclear power plant would be improved by using the validated plant model.

\section{REFERENCES}

[1] Nuclear Safety Analysis Division. RELAP5/MOD3 code manual. NUREG/CR-5535, INEL-95/0174;2003.

[2] Safety Code Development Group. TRAC-PF1/MOD1 An advanced best-estimate computer program for pressurized water reactor thermal hydraulic analysis. NUREG/CR3858, LA-10157-MS;1986.

[3] Atomic Energy Society Japan. Standard method for safety evaluation using best estimate code based on uncertainty and scaling analyses with statistical approach. AESJ-SCS001;2008.

[4] Tian X, Becerra V, Bausch N, Santhosh TV, Vinod G. A study on the robustness of neural network models for predicting the break size in LOCA. Progress in Nuclear Energy, 2018. 109: p. 12-28.

[5] Watanabe T, Anoda Y, Takano M. System-CFD coupled simulations of flow instability in steam generator U tubes. Annals of Nuclear Energy, 2014. 70: p. 141-6.

[6] Katsuyama J, Uno S, Watanabe T, Li Y. Influence evaluation of loading conditions during pressurized thermal shock transients based on thermal-hydraulics and structural analyses. Frontiers of Mechanical Engineering, 2018. 10: p. 1-8.

[7] NEA CSNI. CSNI International standard problems (ISP). NEA/CSNI/R(2000)5: 2000.

[8] Kukita Y, Nakamura H, Watanabe T, Asaka H, Yonomoto T, Suzuki M, Kumamaru H, Anoda Y. OECD/NEA/CSNI international standard problem No. 26 ROSA-IV LSTF cold-leg small-break LOCA experiment comparison report. NEA/CSNI/R(91)13, OECD/NEA/CSNI;1992.

[9] Watanabe T, Kukita Y, Maniwa M. User effects on RELAP5/MOD2 analysis of ROSAIV/LSTF cold-leg break LOCA experiment. International Topical Meeting on Safety of Thermal Reactors, Portland: United States;1991:349-57.

[10] Watanabe T, Kukita Y. Analysis of experiment simulating Mihama Unit-2 steam generator U-tube rupture incident by using RELAP5/MOD2. 28th National Heat Transfer Conference and Exhibition: United States;1992;1-7. 
[11] Watanabe T, Kukita Y. Effects of ECCS and pressurizer auxiliary spray on the experiment simulating Mihama Unit-2 steam generator U-tube rupture incident. Fifth International Topical Meeting on Reactor Thermal Hydraulics (NURETH-5). Salt Lake City: United States; 1992:1013-20.

[12] Hirano M, Watanabe T. Analyses of the Mihama-2 SGTR event and ROSA-IV experiment SB-SG-06 to simulate the event. Fifth International Topical Meeting on Reactor Thermal Hydraulics (NURETH-5). Salt Lake City: United States; 1992:165-73.

[13] Munoz-Cobo JL, Berna C, Escriva A. Top-down scaling methodology from the LSTF facility to a three loop PWR plant applied to a SBLOCA event - The ROSA 1.2 test. Nuclear Engineering \& Design, 2018. 327: p. 248-73.

[14] NEA CSNI. Final Report of OECD/NEA ROSA Project. NEA/CSNI/R(2013)1; 2013.

[15] The ROSA-IV Group. ROSA-IV Large Scale Test Facility (LSTF system description for second simulated fuel assembly. JAERI-M 90-176;1990.

[16] The ROSA-V Group. ROSA-V Large Scale Test Facility (LSTF) system description for the third and fourth simulated fuel assemblies. JAERI-Tech 2003-037;2003.

[17] Nuclear Safety Research Association. Overview of light water nuclear power stations; 2010.

[18] Regulatory Standard and Research Department. Analyses of events for the evaluation of the effectiveness of measures against severe core damage (PWR). NTEC-2014-1001; 2014. 